\title{
Optimization of Wear Behavior of DLC Coatings through Optimization of Deposition Conditions
}

\author{
Ming-Der JEAN ${ }^{1}$, Cheng-Wu LIU ${ }^{2}$, Pao-Hua YANG ${ }^{3}$, Wen-Hsien HO ${ }^{4,5 *}$ \\ ${ }^{1}$ School of Arts and Design, Jimei University, 185 Yinjiang Rd, Jimei District, Xiamen, 361021, China \\ ${ }^{2}$ School of Mechanical and Automotive Engineering, Fujian Provincial Key Laboratory of New Materials Preparation and \\ Forming Technology, Fujian University of Technology, China. No.3 Xueyuan Road, Unversity Town, Minhou, Fuzhou \\ City, Fujian Province, 350118, China \\ ${ }^{3}$ School of Design, Fujian University of Technology, 350118, China \\ ${ }^{4}$ Department of Healthcare Administration and Medical Informatics, Kaohsiung Medical University, 100 Shin-Chuan \\ 1stChina Road, Kaohsiung 807, Taiwan \\ ${ }^{5}$ Department of Medical Research, Kaohsiung Medical University Hospital, 100 Shin-Chuan 1st Road, Kaohsiung 807, \\ Taiwan
}

crossref http://dx.doi.org/10.5755/j01.ms.26.3.22101

\section{Received 20 November 2018; accepted 27 February 2019}

\begin{abstract}
Based on genetic algorithm (GA) and fuzzy neural network, a new method for the study of sputtering process is proposed in this paper. Diamond-like carbon (DLC) coatings were deposited on SKD11 steel by magnetron sputtering. An orthogonal array design is implemented and the effects of control factors on surface properties of the coatings were systematically analyzed. The coating properties were investigated by scanning electron microscopy and Raman spectroscopy, and wear volume surface performance of the Zr-doped DLC coatings was evaluated by a wear tests pinon-disk tribometer. The Raman analyses showed that, at lower ID/IG ratio, a lower wear volume of the $\mathrm{Zr}$-doped DLC coatings can be obtained. Scratch tests as well as Rockwell indentation tests revealed that the graded Zr-doped DLC structures efficiently provide better adhesive strength of DLC coatings. The results show that the wear behaviors of the DLC coatings can be improved by Zr-doping, which the Zr-doped DLC coatings exhibited promising tribological properties. Also, the predictive ability of the GA-ANFIS computations for the tribological behaviors of the Zr-DLC coatings within the experimental domains proved to be reliably obtained, where the forecasted values and experimental results are close.
\end{abstract}

Keywords: damond-like carbon, tribological properties, GA-ANFIS computation, magnetron sputtering deposition, optimization.

\section{INTRODUCTION}

Magnetron sputtering deposition has developed rapidly for the deposition of a wide range of industrially important coatings owing to their largely beneficial properties such as increasing deposition efficiency and decreasing waste of materials, in which many successful applications have been reported in industries including hard, wear-resistant, corrosion resistant, decorative coatings and coatings with specific optical, or electrical properties [1-4]. Sputtering is used extensively in the surface heat-treated industry to deposit thin coatings of various materials in hard resistant wear coatings. It provides efficient solutions to many surface engineering problems and improves the performance and lifetime of various mechanical parts. Several hard coatings such as nitrides, carbides, oxides and borides have widespread applications as protective wear coatings on cutting tools $[5,6]$. Among the hard protective coatings, Diamond-like carbon (DLC) is an excellent combination of high hardness, good wear resistance and low friction coefficient, chemical inertness, and biocompatibility [7]. It has become the most important technique for wear and corrosion protection solutions to the precision moulding application. The major concerns for

${ }^{*}$ Corresponding author. Tel.: +0592-6180809; fax: + 0592-6185889.

E-mail address: whho@kmu.edu.tw (W.H.Ho) many studies on the corrosion and wear problems have been reported, understanding the characteristics of DLC coatings gives favourable results in predicted wear behaviours and controlling wear processes, but do not ensure robust quality on the wear performance of DLC coating [8-11]. Furthermore, sputtering is a process highly affected by a variety of numerous variables and generally reveals nonlinear behaviours. However, due to the coating process being highly nonlinear, time-varying, spatially and stochastically distributed, it is difficult to obtain a satisfactory model to fit the relationships between the coating property as the response variable and numerous explanatory variables using traditional analytical or empirical methods, which make it predict coating properties based on trial and error, have more difficulty yielding satisfactory results. Note that in recent decades, soft computing and or computational intelligent techniques such as fuzzy logic, neural networks and genetic algorithms (GA) in recent decade have much great potential are shown great methods in solving this problem [12-17]. Especially, these powerful methods can provide accurate and desired results in dealing with the coating problems when applied to the magnetron sputtering processes. DLC coatings of magnetron sputtering include the morphologies, microstructures.

However, fewer attempts have been implemented to model the performance of the DLC coating in the 
sputtering processes as well as become more interesting in soft computing and computational intelligent techniques.

Recently, many applications of soft computing /intelligent techniques have attracted much attention in a number of engineering related research fields including system modelling, man-machine control interface, measurements and interpretation, diagnosis and manufacturing due to high adaptive predictive ability $[18,19]$. Artificial intelligent systems and soft computing are comparatively computing techniques that have high learning and predictive capabilities in dealing with the imprecision, uncertainty and nonlinear environment. However, most studies on DLC coatings, which have addressed only the mechanical properties of coatings have seldom considered about correlating variables to known physical phenomena. The use of soft computing techniques is limited for modelling of surface performance of DLC coatings [20-26]. Thus, developing a good forecasting performance in DLC coatings is needed. A hybrid learning algorithm, adaptive network-based fuzzy inference systems (ANFIS), that combines fuzzy systems and neural networks to create a self-adaptive system, in which the system can automatically learn the unknown parameters of nonlinear modelling in under the network-fuzzy architectures and has been attracted widely used growing interest in recent years [27, 28]. However, there are a lot of structure and /parameter combinations, which are difficult to make the ANFIS to behave satisfactorily and; hence the best prediction for the an ANFIS model is limited. However, the better predictor of the ANFIS is difficult to obtain due to the optimization problem for high dimensional data too many parameters that greatly increase the difficulty of the algorithm, especially high-dimension optimal problems. However, given its potential in constructing ANFIS models with reliable predictive predicting capabilities for wear behaviours can be obtained by using GA algorithms, in which the GA-based ANFIS architecture was is considered by finding the best value of the sub-clustering method [29-33].

In this experiment, Zr-doped DLC coatings were introduced using magnetron sputtering depositions and a novel GA-ANFIS system technique for prediction predicting of the tribological behaviours on the sputtering processes was presented in our study. The influence effects of the parameters variables on the microstructure, mechanical properties and wear behaviours of the DLC coatings were analysed. This paper concerns with verifying the novel model method in sputtering process modelling application by adopting tribological data for $\mathrm{Zr}$-doped DLC coatings to construct the GA-ANFIS model. An GAANFIS technique for the prediction of tribological performance by sputtering depositions was developed based on the DLC experiments, in which genetic algorithms can gain the effectiveness of predicting tribological properties on the DLC coatings.

\section{APPARATUSES AND MATERIAL PREPARATION}

A sputtered system is used in this experiment, where a sputter magnetic field design supplying four rectangle targets $(300 \times 100 \times 10 \mathrm{~mm})$ is operated in an unbalanced mode. For the four targets with a $99.5 \%$ zirconium target of $99.5 \%$, and three a $99.5 \%$ carbon target of $99.5 \%$ were adopted in the system. The Zr-doped DLC coatings including interlayers as $\mathrm{Zr}$ (Layer1) $\mathrm{ZrC}$ (Layer2) elements, and $\mathrm{CN}$ coatings with $\mathrm{Zr}$ additives (Layer3) were conducted. The substrate matrices used in the experiments were the compositions of SKD11 steel with dimensions of $4 \mathrm{~cm} \times 4 \mathrm{~cm} \times 0.45 \mathrm{~cm}$ (Table 1) and silicon wafers with dimensions of $2 \mathrm{~cm} \times 2 \mathrm{~cm} \times 0.1 \mathrm{~cm}$.

Table 1. The factors and levels of the graded Zr-doped DLC coatings, with two interlayered layers of $\mathrm{Zr}$ and $\mathrm{ZrC}$, for the sputtering processes

\begin{tabular}{|l|c|c|l|c|c|c|}
\hline & Layer & Layer & \multicolumn{4}{|c|}{ Layer 3 } \\
\hline Factors & 1 & 2 & Factors & Level 1 & Level 2 & Level 3 \\
\hline Ar, sccm & 30 & 30 & A: Bias & 40 & 60 & 80 \\
\hline Bias, -V & 110 & 45 & $\begin{array}{l}\text { B: Pulse } \\
\text { requency }\end{array}$ & 50 & 100 & 150 \\
\hline $\begin{array}{l}\text { Frequency, } \\
\text { kHz }\end{array}$ & 50 & 50 & C: CH 4 & 2 & 5 & 8 \\
\hline Time, min & 20 & 10 & $\begin{array}{l}\text { D: } \\
\text { Sputtering } \\
\text { distance, } \\
\text { cm }\end{array}$ & 8 & 10 & 12 \\
\hline $\begin{array}{l}\text { Cr/Zr } \\
\text { current, A }\end{array}$ & $0 / 1$ & $2.3 / 0.4$ & $\begin{array}{l}\text { E: C/Ze } \\
\text { current }\end{array}$ & $2.3 / 0.3$ & $2.3 / 0.6$ & $2.3 / 0.9$ \\
\hline
\end{tabular}

The substrates were ultrasonically cleaned in methanol and acetone for $10 \mathrm{~min}$ each, and fixed on a cylindrical sample holder in the vacuum chamber and then was dried using ion bombardment in an Ar plasma discharge before deposition. The surface morphologies and worn scars of the DLC coatings were analysed in a field emission scanning electron microscope (JEOL JSM-6700F) varied from $0.5 \mathrm{kV}$ to $30 \mathrm{kV}$. The elemental composition of the coatings was investigated by energy dispersive X-ray spectroscopy (EDX). The measurements were achieved for a surface area of $1.05 \mathrm{~mm}^{2}$. The deposited coatings were characterized by Raman spectra, where the binding structures of the DLC coatings were examined using a laser Raman spectrometer (SPEX 1403, USA) with a HeNe laser beam of $632.8 \mathrm{~nm}$ as the excitation source. A laser power up to $50 \mathrm{~mW}$ using a back-thinned charged-coupled device array detector covering $1300-1600 \mathrm{~cm}^{-1}$ and a $785 \mathrm{~nm}$ laser shift (Stokes) at $5 \mathrm{~cm}^{-1}$ resolution, with a spot diameter of $1.1 \mu \mathrm{m}$ and spectral acquisition conditions were 1-s exposure time with 10 accumulations Rockwell Hardness Test (ASTM E18) with a diamond cone indenter and a maximum test load of 50 kilograms is used. It used to assist in determining the grade of coatings. The hardness of the DLC-coated SKD11 specimen was measured on the surface of the coatings by using a microindenter. To evaluate the tribological behaviour, wear tests were carried out using a pin-on-disk tribometer (ASTM G99). The friction and wear properties of the DLC coating were performed under the following conditions. The counterpart was a tungsten carbide ball with a diameter of $12 \mathrm{~mm}$. The normal load was $0.3 \mathrm{kgf}$ with a sliding diameter of $20 \mathrm{~mm}$. The sliding speed was $0.3 \mathrm{~m} / \mathrm{s}$ and the sliding distance was $1000 \mathrm{~m}$. The friction coefficient and wear rate of SKD11 stee are $0.68 \mu$ and $10^{-4} \mathrm{~mm}^{3} / \mathrm{Nm}$. The wear tracks and scars of the coatings were measured by a TalyScan 150 
(Taylor Hobson, Leicester, U.K.) and were observed by SEM. This surface profiler instrument may obtain the wear profile information, in which the resulting wear volume was calculated by a computer.

\section{EXPERIMENTS}

\subsection{Experimental design}

The factors and levels of the graded $\mathrm{Zr}$-doped DLC coatings with two interlayered layers of $\mathrm{Zr}$ and $\mathrm{ZrC}$ for the sputtering processes are shown in Table 1. Most of five factors of layer 3 in the orthogonal array have three levels. An experiment based on the orthogonal array allows the even effects of factorial interactions over five parameters variables by a self-balancing property to be efficient, and experimental trials in robust design are organized. The complete details of the coating deposition are mentioned in Table 2, with each trial containing a different combination of levels and factors. It consists of 18 individual experiments corresponding to the 18 rows.

Table 2. Control factors and wear performance estimate with wear rate, standard deviation and $\mathrm{S} / \mathrm{N}$ ratio for DLC film coatings

\begin{tabular}{|l|c|c|c|c|c|c|c|c|}
\hline $\begin{array}{l}\text { No. } \\
\text { of } \\
\text { tests }\end{array}$ & Control factors & B & C & D & E & Wear rate & $\begin{array}{l}\text { Standard } \\
\text { deviation }\end{array}$ & $\begin{array}{l}\text { S/N } \\
\text { ratio }\end{array}$ \\
\cline { 4 - 10 } & & & & & $\begin{array}{c}10^{-5} \\
\mathrm{~mm}^{3} / \mathrm{Nm}\end{array}$ & $\begin{array}{c}10^{-5} \\
\mathrm{~mm}^{3} / \mathrm{Nm}\end{array}$ & $\mathrm{dB}$ \\
\hline L1 & 1 & 1 & 1 & 1 & 1 & 16.6 & 6.07 & 35.89 \\
\hline L2 & 1 & 2 & 2 & 2 & 2 & 4.63 & 1.99 & 46.19 \\
\hline L3 & 1 & 3 & 3 & 3 & 3 & 17.59 & 3.20 & 35.00 \\
\hline L4 & 2 & 1 & 2 & 2 & 3 & 19.57 & 2.52 & 34.12 \\
\hline L5 & 2 & 2 & 3 & 3 & 1 & 22.44 & 3.42 & 32.91 \\
\hline L6 & 2 & 3 & 1 & 1 & 2 & 9.16 & 0.86 & 40.74 \\
\hline L7 & 3 & 1 & 1 & 3 & 3 & 18.14 & 2.84 & 34.76 \\
\hline L8 & 3 & 2 & 2 & 1 & 1 & 17.26 & 1.8 & 35.23 \\
\hline L9 & 3 & 3 & 3 & 2 & 2 & 12.11 & 1.44 & 38.29 \\
\hline L10 & 1 & 1 & 3 & 2 & 1 & 19.66 & 1.39 & 34.11 \\
\hline L11 & 1 & 2 & 1 & 3 & 2 & 15.55 & 2.05 & 36.11 \\
\hline L12 & 1 & 3 & 2 & 1 & 3 & 9.19 & 1.18 & 40.68 \\
\hline L13 & 2 & 1 & 3 & 1 & 2 & 10.62 & 0.73 & 39.46 \\
\hline L14 & 2 & 2 & 1 & 2 & 3 & 6.50 & 1.97 & 43.48 \\
\hline L15 & 2 & 3 & 2 & 3 & 1 & 18.41 & 5.93 & 34.41 \\
\hline L16 & 3 & 1 & 2 & 3 & 2 & 13.84 & 8.60 & 36.18 \\
\hline L17 & 3 & 2 & 3 & 1 & 3 & 15.19 & 1.33 & 36.34 \\
\hline L18 & 3 & 3 & 1 & 2 & 1 & 15.31 & 1.42 & 36.27 \\
\hline
\end{tabular}

The five columns of the matrix represent the five factors with three levels, as indicated in the table. The tendencies of control factors, as well as how they may affect robustness, are evaluated. However, three categories regarding desired types of the quality of characteristics in the analysis of the $\mathrm{S} / \mathrm{N}$ ratios are conducted, that is, the lower and the better, the higher and the better, and the nominal and the better types. In this paper, the tribological property of the Zr-doped coatings is of a smaller type. Further, an analysis of variance (ANOVA) is also used to determine which design parameters variables have a significantly effect influence in this experiment and then are included considering the modelling in GA-ANFIS.

\subsection{Tribological performance estimate using the $\mathrm{S} / \mathrm{N}$ ratios}

For a DLC coating, a decreased wear volume value of the coating after a wear test will yield a better tribological performance. As a result, its quality characteristic is the smaller and the better type. To understand the tribological behaviors of the DLC coatings, the experimental data will be transformed to Signal-to-Noise ratios ( $\mathrm{S} / \mathrm{N}$ ratio) that attempted to combine information about the mean and variance, and then to a decibel form [13, 14]. However, to reduce cost and time, three repeated measures measurements of experimental data for each set of chosen tests were taken. Eq. 1 calculates the $\mathrm{S} / \mathrm{N}$ ratios for the smaller the better type. The $\mathrm{S} / \mathrm{N}$ ratio $\left(\eta_{\mathrm{i}}\right)$ as the criterion index was used to evaluate the quality characteristics of tribological performance using the logarithmic equation:

$\eta_{\mathrm{i}}=-10 \log \left[\frac{1}{\mathrm{n}} \sum_{\mathrm{i}=1}^{\mathrm{n}}\left(\overline{\mathrm{y}}_{\mathrm{i}}^{2}+\mathrm{s}_{\mathrm{i}}^{2}\right)\right]$,

where $\eta_{\mathrm{i}}$ is the $\mathrm{S} / \mathrm{N}$ ratios of the wear rate value for the $\mathrm{i}^{\text {th }}$ test and $\mathrm{n}$ is the total number of tests. The average value, standard deviation, and $\mathrm{S} / \mathrm{N}$ ratios of three repeated runs of the wear rate were performed as shown in Table 2.

\subsection{Adaptive network-based fuzzy inference system}

ANFIS is a well-known hybrid method that integrates the merits of the neural networks and the fuzzy logic to develop models while simultaneously offset their own shortcomings. ANFIS uses fuzzy logic principles to establish the input-output relationship through a rule based inference engine with fuzzy if-then rules, the membership functions and an inference system. By utilizing learning ability of neural networks in tuning relationship between input-output variables in fuzzy inference system, the structure in ANFIS can be established. It provides the fuzzy system with neural learning capabilities for solving nonlinear sputtering problems.

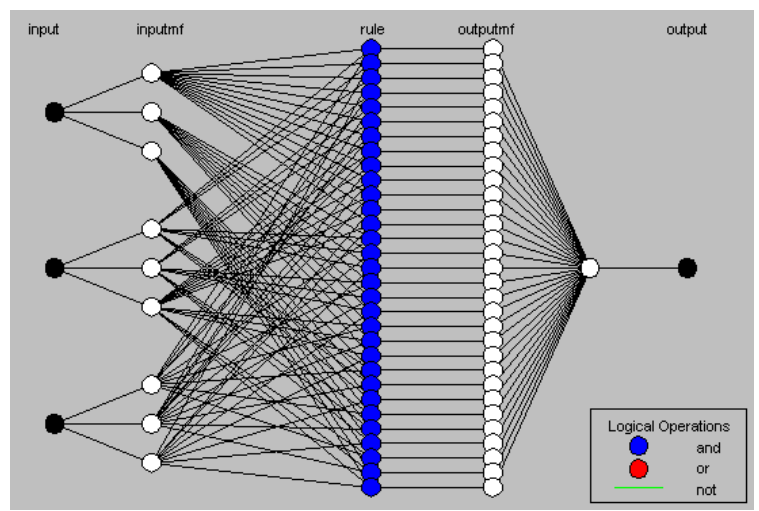

Fig. 1. The corresponding 5-layer neural network that participates in the construction of the fuzzy rules after the GA learning

In this study, it provides an effective approach to fit the relationship between variables and the tribological property. However, this technique has shown significant results in modeling nonlinear functions and converges faster compared to other fuzzy models. A detailed description of the adaptive fuzzy system algorithm was 
described in [21-23]. A typical architecture of an ANFIS, in which a blue circle indicates a fixed node, whereas a white circle indicates an adaptive node, is shown in Fig. 1. In ANFIS, the structure of the fuzzy if-then rules including the antecedent part of the Mamdani and the consequent part of the Takagi-Sugeno model is utilized. The rule base contains $\mathrm{k}$ number of fuzzy if-then rules of Takagi and Sugeno's type as follows:

$R_{\mathrm{j}}: \mathrm{IF} \mathrm{x} 1$ is $\mathrm{A}_{1}{ }^{\mathrm{j}}$ and $\mathrm{x}_{2}$ is $\mathrm{A}^{\mathrm{j}}$ and ... and $\mathrm{x}_{\mathrm{n}}$ is $\mathrm{A}_{2}{ }^{\mathrm{j}}$, then $\mathrm{y}^{\mathrm{j}}=\mathrm{f}\left(\mathrm{x}_{1}, \mathrm{x}_{2}, \ldots, \mathrm{x}_{\mathrm{n}}\right), \mathrm{j}=1,2, \ldots, \mathrm{k}, \mathrm{i}=1,2, \ldots, \mathrm{n}$,

where $x_{i}$ is the antecedent input, $A^{j}$ is the linguistic labels of the fuzzy set and $f\left(x_{1}, x_{2}, \ldots, x_{\mathrm{n}}\right)=p_{j} B+q_{j} D+r_{j} E+t_{j}$, is a first order polynomial. In ANFIS, the variables $B, D, E$ in the antecedent and $\mathrm{p}_{j}, \mathrm{q}_{\mathrm{j}}, \mathrm{r}_{\mathrm{j}}, \mathrm{t}_{\mathrm{j}}(\mathrm{j}=1,2,3 \ldots 27)$ in the consequent are fuzzy variables. Based on the facts in the IF part of the rule, the rule enables approximate reasoning in the THEN part. Further, the aggregated output of the model is computed by taking the weighted average of the individual fired rule. The ANFIS used in this study is a Takagi and Sugeno type system in which the if-then rules are constructed from the input- output pairs and it structure consists of five layers as seen in Fig. 1 including fuzzification, fuzzy set database, fuzzy rule base, decision making and defuzzification. The inferred ANFIS output from Eq. 3 is represented as

$y=\sum_{\mathrm{j}=1}^{\mathrm{n}} \overline{W_{\mathrm{j}}} \mathrm{f}\left(\mathrm{x}_{1}, \mathrm{x}_{2} \ldots, \mathrm{x}_{1}\right)$,

where $y$ denotes the inferred output of the ANFIS, and $W=\mathrm{W}_{1} / \sum^{n} W_{j}$ is the average fired rule, which the fired degree of the lth rule is given by

$W_{j}=\prod \mu_{i j\left(x_{i}\right)}(I=1,2,3 . . n ; j=1,2,3, \ldots k)$.The membership function of Gaussian is defined in Eq. 4 in the ANFIS model. The measured performances with a Gaussian function were normalized using standard min-max normalization procedure. The Gaussian membership functions are adopted as follows:

$\mu_{A_{j}^{\mathrm{i}}}\left(\mathrm{x}_{\mathrm{i}}\right)=\exp \left[-\frac{\sum_{\mathrm{i}}\left(\mathrm{x}_{\mathrm{i}}-\beta_{\mathrm{ij}}\right)^{2}}{2 \mathrm{a}_{\mathrm{ij}}^{2}}\right]$,

where $\left(\alpha_{\mathrm{ij}}, \beta_{\mathrm{ij}}\right)$ is the parameter set of the membership functions in the fuzzy if-then rules. $\alpha_{\mathrm{ij}}$ denotes the width of the Gaussian membership function and $\beta_{\mathrm{ij}}$ is the center of the Gaussian membership function, respectively, building the Gaussian functions accordingly. ANFIS employs gradient descent to fine-tune Gaussian functional parameters $\left(\alpha_{\mathrm{ij}}, \beta_{\mathrm{ij}}\right)$. In addition, ANFIS also uses the leastsquares method to identify consequent linear parameters $\left(\mathrm{p}_{\mathrm{j}}, \mathrm{q}_{\mathrm{j}}, \mathrm{r}_{\mathrm{j}}, \mathrm{t}_{\mathrm{j}}\right)$, which two learning methods in order to reduce errors are applied in ANFIS to optimize the relationship between input and output.

\subsection{Genetic algorithms-based ANFIS approaches}

To solve a combinatorial optimization problem, the Genetic Algorithms (GA) proposed by Holland [16] that is an optimization based on the ideas of natural selection and evolutionary processes created the better genes to evolve towards a population that is expected to obtain the best solution. Moreover, the use of a hybrid learning algorithm in ANFIS combining the gradient method and the least squares based on both human knowledge and the stipulated input-output data pairs are to determine the modifiable parameters to make reliable modelling, where several problems were met during the calibration of the ANFIS parameters. This learning algorithm is still limited in which they only caught in the local optimal solution with a great amount of parameters. Noticeably, the GA method for identifying optimal parameters of ANFIS can offer excellent search solutions of many kinds compared to the hybrid learning algorithm in the ANFIS. In this paper, the GAs based on the ANFIS are applied because the GAANFIS may obtain both better and more robust learning information than the ANFIS reported in [12]. The detailed steps of the GA-ANFIS are described in Chou [31]. In the GA, both the crossover and mutation are optimized in the Taguchi method such as $\mathrm{S} / \mathrm{N}$ ratios and orthogonal arrays. By using the $J$ in Eq. 5, the fitness values of the initial population can be calculated.

To determine the probability of the crossover, a roulette wheel approach and a crossover rate are used. Accordingly, in the Taguchi method, the better genes that are systematically screened in the crossover operations are used to enhance the genetic algorithms. In this experiment, the orthogonal array, $\mathrm{L}\left(2^{127}\right)$, is utilized and the fitted values from Eq. 5 are calculated. Using the error measure, the effects of the various factors are explored. After repeating above steps, the population based on the Taguchi method is created, a mutation is operated and better chromosomes are obtained, and thus the genetic algorithms are enhanced. Besides, more detailed information can be found in MATLAB users'manual [17] and Tsai [18]. In this paper, the root mean square error (RMSE) criterion that the premise parameters $\left(\alpha=\left[\alpha_{\mathrm{ij}}\right], \beta=\left[\beta_{\mathrm{ij}}\right]\right)$ and the consequent $(\mathrm{Y}=[\mathrm{pl}, \mathrm{ql}, \mathrm{rl}, \mathrm{tl}])(\mathrm{l}=1,2, \ldots, 27)$ are used in the ANFIS is determined. Computations in ANFIS were carried out using MATLAB 7, mathematical software with fuzzy logic toolboxes. Accordingly, the RMSE criterion $J$ underlying the ANFIS network is expressed as:

$$
\boldsymbol{J}=\left[\sum_{\mathrm{l}=1}^{\mathrm{n}} \frac{\left(\mathrm{R}-\mathrm{y}_{\mathrm{l}}\right)^{2}}{\mathbf{n}}\right]^{\frac{1}{2}},
$$

where $R_{l}$ is the experimental data, $y_{l}$ is the predicted value of ANFIS, and $n$ is the number of training/testing data. As expected, the optimization of parameters such as premise nonlinear parameters and consequent linear parameters in the ANFIS are identified by the GA method. In the GA, the specified error tolerance is used to check whether an ANFIS has yielded an efficient model following sufficient iterations. Based on the concept above, this paper proposes a novel method to the tribological properties of the graded Zr-DLC coatings. The GA is applied to refine the parameters of rules in the ANFIS model for forecasting the tribological performance of DLC coatings, in which experimental data are given to make an accuracy comparison with those obtained by the GA-ANFIS model. 


\section{RESULTS AND DISCUSSION}

\subsection{Tribological performance}

Table 2 displays the experimental layout and all experimental results. The wear rate values ranged between $4.63 \times 10^{-5} \mathrm{~mm}^{3} / \mathrm{Nm}$ and $22.44 \times 10^{-5} \mathrm{~mm}^{3} / \mathrm{Nm}$ of are appeared in the DLC coatings. The wear performance of each trial for DLC coatings is evaluated by their $\mathrm{S} / \mathrm{N}$ ratios with the wear rate values and standard deviations. Most wear rate values of the DLC coated specimens were almost low than the SKD11 specimens, displaying good anti-wear performance. For Table 2, the $\mathrm{S} / \mathrm{N}$ ratios for Trials 2, 5 and 13 are $46.19 \mathrm{~dB}, 32.94 \mathrm{~dB}$ and $39.46 \mathrm{~dB}$, respectively. This $\mathrm{S} / \mathrm{N}$ ratio increase in sample 2 is much greater than in other tests in which the worn volume value reduced from $14.4 \times 10^{-3} \mathrm{~mm}^{3}$ to $6.88 \times 10^{-3} \mathrm{~mm}^{3}$, indicating a highly dense coating. Note that a smaller wear volume value induces a higher $\mathrm{S} / \mathrm{N}$ ratio. Furthermore, the SEM micrographs of surface with the EDS spectrum and crosssection morphology of DLC coatings with the wear volume values are compared as shown in Fig. 2. The coating of Fig. $2 \mathrm{a}-\mathrm{d}$ that $57.5 \%$ carbon and $17.50 \%$ zirconium are detected possessed extremely dense, indistinct compact structure and its surface with the formation of $\mathrm{CN}$ particles is more homogenous, leading to higher $\mathrm{S} / \mathrm{N}$ ratio. In contrast, the fracture coatings in Fig. 2 b-e, $63.33 .03 \%$ carbon and $19.27 \%$ zirconium possessed obviously columnar structure and in Fig. 2 c-f, $67.09 \%$ carbon and $18.18 \%$ zirconium shows looser, tearing structural features or defects and its surface is a grainy texture, where no significant difference between zirconium elements of the DLC coatings is found except that sample 2 reveals lesser amount of zirconium elements. However, the decrease of surface textures by less doped $\mathrm{Zr}$ for the DLC coatings was smoothing, while in the dense microstructures, a considerable less amount of carbon is also appeared.

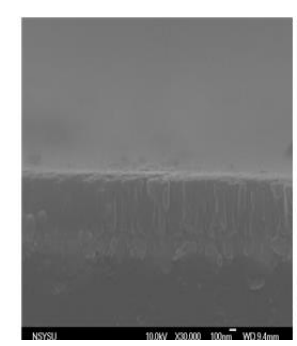

a

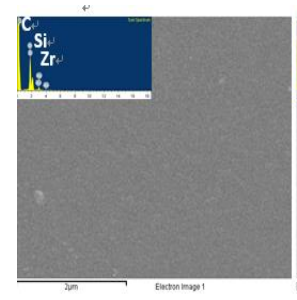

$\mathrm{d}$

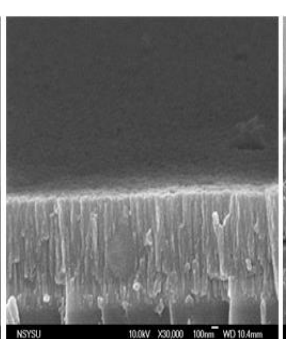

b

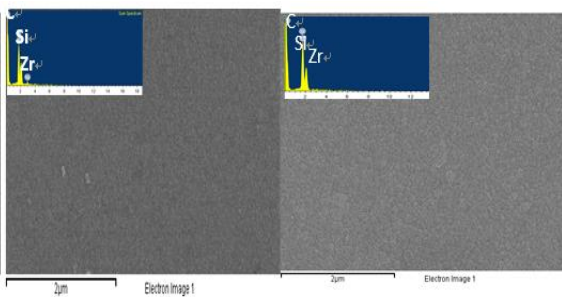

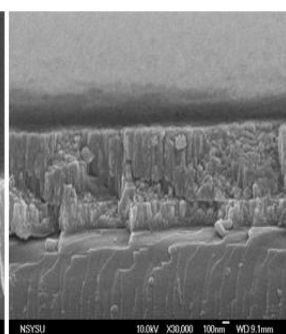

c f
Fig. 2. SEM images with EDS analysis of the cross-section and top-viewed micrographs of various graded $\mathrm{Zr}$-doped DLC coatings with: a, d-trial 2; b,e-trial 13; c, f-trial 5

\subsection{Structural evolution analysis}

Table 3 shows the Raman spectra including a D-peak and a G-peak positions with the bands' intensity and width, microhardness, wear volume and the peak intensity ratio $\left(\mathrm{I}_{\mathrm{D}} / \mathrm{I}_{\mathrm{G}}\right)$ of the four DLC debris samples, which is the area ratio of the $D$ peak to the $G$ peak, in these spectra reflect the clustering and disorder of the $\mathrm{sp}^{3} / \mathrm{sp}^{2}$ sites for coatings obtained from $\mathrm{Zr}$-doped DLC coatings. All DLC coatings that can be obtained by the broad peak at $1100-1700 \mathrm{~cm}^{-1}$ region show fitted features in their Raman spectra, where the Raman spectra of the DLC coatings mainly dominated as two Gaussian peaks, including a D (disordered) peak at approximately $1350 \mathrm{~cm}^{-1}$ and a $\mathrm{G}$ (graphite) peak at around $1580 \mathrm{~cm}^{-1}$ [10], corresponding to the $\mathrm{sp}^{3}$ and $\mathrm{sp}^{2}$ bonding, respectively.

Table 3. Raman spectra of worn DLC debris collected. D peak position ( $\mathrm{xD}), \mathrm{G}$ peak position $(\mathrm{xG})$, and the ratio of the D-band to G-band intensity $\left(\mathrm{I}_{\mathrm{D}} / \mathrm{I}_{\mathrm{G}}\right)$ of the deposited DLC coatings

\begin{tabular}{|c|c|c|c|c|c|c|c|c|}
\hline \multicolumn{3}{|c|}{ Peak shift } & \multicolumn{2}{|c|}{ FWHM } & \multirow{3}{*}{$\mathrm{ID} / \mathrm{I}_{\mathrm{G}}$} & \multicolumn{2}{|c|}{$\begin{array}{c}\text { Coating } \\
\text { properties }\end{array}$} & \multirow{2}{*}{$\begin{array}{l}\mathrm{S} / \mathrm{N} \\
\text { ratio }\end{array}$} \\
\hline \multirow{2}{*}{ Tests } & D-b & G-band & D-band & $\begin{array}{l}\text { G- } \\
\text { band }\end{array}$ & & $\begin{array}{l}\text { Hard- } \\
\text { ness }\end{array}$ & $\begin{array}{l}\text { Wear } \\
\text { loss }\end{array}$ & \\
\hline & $\omega_{\mathrm{D}} \mathrm{cm}^{-1}$ & $\omega_{\mathrm{DCm}}^{-1}$ & $\mathrm{~cm}^{-1}$ & 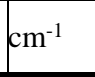 & & $\mathrm{Hv}$ & $\begin{array}{l}10^{3-} \\
\mathrm{mm}^{3} \\
\end{array}$ & $\mathrm{~dB}$ \\
\hline $\mathrm{L} 2$ & 1387.1 & 155 & 208.18 & 112.96 & 1.28 & 2492 & 6.88 & 46.19 \\
\hline L5 & 1371.33 & 1570.71 & 234.74 & 101.98 & 1.92 & 1374 & 13.3 & 32.91 \\
\hline L10 & 1364.19 & 1579.04 & 182.00 & 102.09 & 1.84 & 1335 & 14.4 & 34.11 \\
\hline L14 & 1383.65 & 1572.16 & 207.45 & 96.99 & 1.39 & 2499 & 7.33 & 43.48 \\
\hline
\end{tabular}

In the case of sample 2, the lower ID/IG is obtained in which the D-band position was centered at $1387.10 \mathrm{~cm}^{-1}$ and was higher than that of the others, while the G-band position was centered at $1557.03 \mathrm{~cm}^{-1}$ and shifted to lower values than that of the others. The hardness value of the DLC coating samples that was measured using microindentation is also listed in Table 3. For the Zr-DLC multilayer coatings, the $G$ peak was shifted to lower Raman shift from the graphite position at $1580 \mathrm{~cm}^{-1}$, indicating that their structure is considerable amount of graphite-like $\mathrm{sp}^{2}$ bonds, in company with diamond-like $\mathrm{sp}^{3}$ bonds. However, the lower ID/IG ratio in Raman spectra produced higher tribological properties among the DLC coatings. This finding is consistent with literature [18]. As can be seen in Table 3, for the lower wear volume, the sharp peak at $1387 \mathrm{~cm}^{-1}$ is characteristic of the $\mathrm{sp}^{3}$ bonding of diamond and indicative of higher phase-purity polycrystalline diamond. The larger shift to $1387 \mathrm{~cm}^{-1}$ of D-band peak in the wavenumbers at $1360 \mathrm{~cm}^{-1}$ and the Gband peak located to lower Raman shift to $1557 \mathrm{~cm}^{-1}$ from $1580 \mathrm{~cm}^{-1}$ is owing to generation of the zirconium microcrystalline, where the hardness decreases directly with the $\mathrm{I}_{\mathrm{D}} / \mathrm{I}_{\mathrm{G}}$ ratio increase in the spectra of the DLC coatings prepared. The integrated intensity ratio of the Gaussian shape for the lower wear volume was $\mathrm{I}_{\mathrm{D}} / \mathrm{I}_{\mathrm{G}}=1.28$ and the FWHM $\left(\mathrm{cm}^{-1}\right)$ for D and G peaks were 208 and 113 respectively. The maximum wear volume value was $63.30 \times 10^{-3} \mathrm{~mm}^{3}$ and the minimum wear rate value $6.88 \times 10^{-3} \mathrm{~mm}^{3}$ for the $\mathrm{Zr}$-DLC coatings under a normal load of $10 \mathrm{~N}$, following $1000 \mathrm{~m}$ of sliding. It is clear that 
the higher hardness value and the lower worn volume are appeared at lower the $\mathrm{I}_{\mathrm{D}} / \mathrm{I}_{\mathrm{G}}$ ratio.

The Raman spectra of four debris samples shown in Fig. 3 differ from each other within the visible wave range. As shown in Fig. 3 a, all the two peaks are represented by Gaussian functions. As evident in the figures, the Raman shifts of two peaks were obtained. The peak at $4 \%$ above $1350 \mathrm{~cm}^{-1}$ is the D-band and the other at $5 \%$ below $1580 \mathrm{~cm}^{-1}$ is the G-band. This phenomenon was attributed to the formation of zirconium clusters of carbon networks in the DLC coatings, and consequently, the locations of the D-band and the G-band in the DLC coatings were shifted. However, with further increase in $\mathrm{I}_{\mathrm{D}} / \mathrm{I}_{\mathrm{G}}$, G-band peak position is about $1580 \mathrm{~cm}^{-1}$, indicating more graphitic structure $\left(\mathrm{sp}^{2}\right)$.

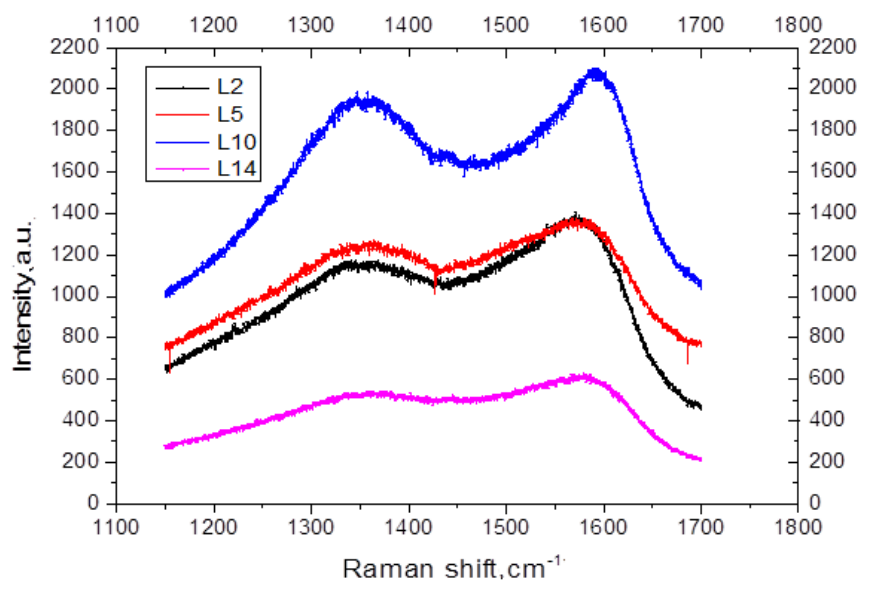

a

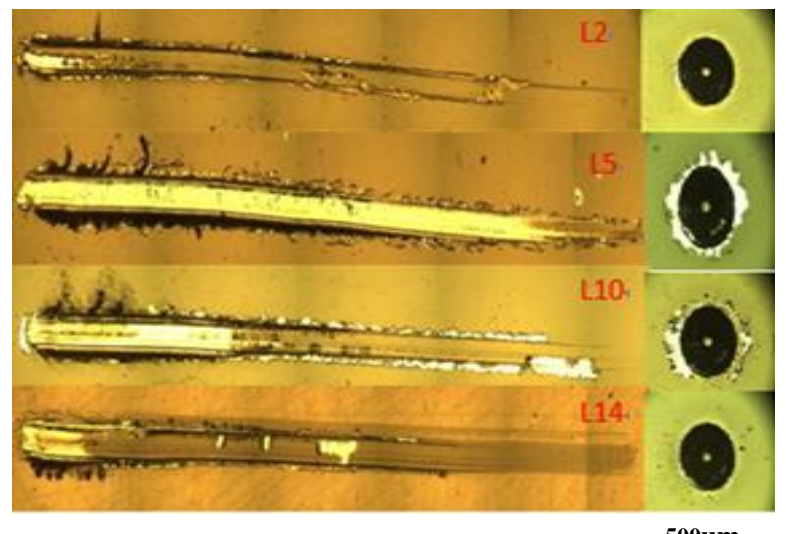

500um

b

Fig. 3. a-typical Raman spectra of the a-C coatings deposited on a silicon wafer. The spectrum is deconvoluteable into two Gaussian peaks centered at around $1360 \mathrm{~cm}^{-1}$ (D-band) and $1580 \mathrm{~cm}^{-1}$ (G-band); b-scratched tracks and Rockwell tests

It can be seen from the plot that the G-band peak position shifts down, the peak intensity ratio $\left(\mathrm{I}_{\mathrm{D}} / \mathrm{I}_{\mathrm{G}}\right)$ also shifts to lower values with decreasing wear rate and increasing hardness, indicating yield a higher $\mathrm{S} / \mathrm{N}$ ratio. According to theoretical work by Beeman et al [19], a shift of the Raman G-peak to lower frequency indicates a greater $\mathrm{sp}^{3} / \mathrm{sp}^{2}$ bonding ratio. On the other hands, as evident in Fig. 3, the half-width of the separated D peak is large, such that the half-width of the $\mathrm{D}$ peak is larger than the half-width of the $\mathrm{G}$ peak, resulting in a decrease in the hardness. As can be seen in the figures, the wear volume of the DLC coatings decreased as the peak intensity ratio $\left(\mathrm{I}_{\mathrm{D}} / \mathrm{I}_{\mathrm{G}}\right)$ decreased. It is clearly shown $\mathrm{Zr}$-DLC types of coatings are composed of amorphous and some nanocrystalline grains, which are dispersed in the SKD11 matrix. Fig. $3 \mathrm{~b}$ shows the optical photos of the scratch tracks and Rockwell indentation tests of zirconia doped DLC coatings, where the graded structures can improve the adhesion of DLC coatings. From the photos presented in Fig. 3, in the case of sample 5 with higher IG position, which the adhesion failure load is $19 \mathrm{~N}$, the trace shows the clear flaking extended to the end of scratching after scratched and part of the DLC coating surrounding the indentation was detached, which can be classified into adhesion level HF5. In the case of sample 10, the adhesion failure load of coatings is $54 \mathrm{~N}$, which the track flaking of sample 10 was almost one-half as much less as sample 5 . While for sample 2 with high adhesion failure load of $72 \mathrm{~N}$, no obvious spalling after Rockwell indentation, corresponding to HF1 level, was observed. The traces show only a little larger flaking closer to the end of scratching, but a little bit of chipping of DLC coatings, resulting in a better adhesion. Comparing to the scratch track photo of sample 14, the mechanism of adhesion failure of coatings exhibited similar failure behaviors and the delamination of several small areas appeared around the Rockwell indentations. These results verify that the lower $\mathrm{I}_{\mathrm{D}} / \mathrm{I}_{\mathrm{G}}$ ratio could sustain much higher scratch stresses and better wear resistance. The results comparison obtained by the analyses of Fig. 3 shows that the adhesion failure of DLC coatings with decreasing $\mathrm{I}_{\mathrm{D}} / \mathrm{I}_{\mathrm{G}}$ was noticeably improved by graded Zr-doped DLC coatings on the SKD11substrate. This is due to existing a graded interface between the DLC coating and substrate resulting in stress reduction in the interface and thus enhancing the adhesion as it was reported by other authors $[4,25]$. Similarly, in Fig. 3 b, sample14 displays few slight dimples and long narrow furrows on the worn surface of the coatings. Its wear mechanism is essentially abrasion wear from ploughing and grooving in the worn surface. On the other hand, the level of $6.50 \times 10^{-5} \mathrm{~mm}^{3} / \mathrm{Nm}$ of the wear rate is also low in the sputtering experiments, in which the wear scar volume has a value of $9.16 \times 10^{-3} \mathrm{~mm}^{3}$ with the width increasing slightly to the value of $1.30 \mathrm{~mm}$. Fig. $3 \mathrm{c}$ shows the mainly micro-ploughing and brittle fracture scars with a slender area are appeared and the peel-off area of DLC coatings is also produced. As shown in Fig. 3 d, in the higher wear rate coatings, the width of the wear track is very large, the galling and fracture of DLC coatings occurred after $1000 \mathrm{~m}$ sliding and many scratches were induced along the wear direction, in which the wear scar volume is relatively large value of $63.30 \times 10^{-3} \mathrm{~mm}^{3}$ with the width increasing rapidly to the value of $1.85 \mathrm{~mm}$. This is consistent with the result obtained from the SEM images. Clearly, the worn track profile in sample 5 obtained from the present study irregularly fluctuates in the wear track topography while the worn track in sample 2 becomes less undulated to be a comparatively fine texture. As anticipated, the Zr-doped DLC coatings with the smaller wear volume showed the best wear behavior in the Zr-doped DLC coatings. Overall, 
the comparison of these figures clearly shows that the volume losses of surface removal in SKD11 sample is much more than that of as-sputtering samples. The wear volume shown in Fig. 3 reveals that the $\mathrm{Zr}$-doped DLC coatings have considerable improvement during wear test, which offered better the tribological behaviors. In addition, the frictional coefficient behaviors of the Zr-doped DLC coatings against tungsten carbide are shown in Fig. 4 e, presenting the variation in frictional coefficient with the sliding distances of $1000 \mathrm{~m}$. Sample 2 yielded the lowest coefficient of friction (COF) of 0.28 , whereas sample 5 showed the highest COF of 0.84 among DLC-coated samples. The frictional curve increased from an initially low value to a steady state except sample 5 in all cases. In the case of sample 10, the COF reduces from 0.77 to 0.56 whereas sample 5 showed a rapid increase slight reduction in increases with the initial to $400 \mathrm{~m}$ from 0.4 to 0.8 , and became instability with drastic fluctuations as sliding distance over sliding $400 \mathrm{~m}$. An increase in the wear rate of the $\mathrm{Zr}$-doped DLC coatings in with a greater COF is clear. As discussed previously, this can be attributed to the change in lubricant coating from DLC to the $\mathrm{Zr}$-doped DLC lubricant. An increase in the wear rate of the $\mathrm{Zr}$ doped DLC coatings with a greater COF is clear. Overall, the Zr-DLC coatings possessed the higher anti-wear properties. This is attributed to the formation of hard $\mathrm{Zr}$ element transfer coating on the worn scar, in which the containing graphite of the Zr-doped DLC coatings in sliding is seen, and the lubricating surface layer is generated. This finding was confirmed by Raman spectroscopy. Therefore, the wear mechanism resulting in lower friction and wear can effectively enhance the antiwear behavior of the Zr-doped DLC coatings.

\subsection{Wear surface properties}

Table 2 shows the experimental data, standard deviation and $\mathrm{S} / \mathrm{N}$ ratios for the Zr-doped DLC coatings. The wear performance of each experimental trial for the Zr-doped DLC coatings is evaluated by computing their $\mathrm{S} / \mathrm{N}$ ratios. The results showed considerably different tribological behaviors. Most wear rates of the coated specimens after sliding wear were relatively small, around the level of $10^{-5} \mathrm{~mm}^{3} / \mathrm{Nm}$, compared with others $[11,26,27]$, indicating a better wear performance. As shown in Table 2, the decrease in the wear rate of the $\mathrm{Zr}$ DLC coatings in the with a greater $\mathrm{S} / \mathrm{N}$ ratio is seen. The wear tracks and scars of the Zr-DLC coatings are examined by SEM as shown in Fig. 4, showing the four different wear scars, and the structure of the wear surface significantly varied. Fig. $4 \mathrm{a}$, in the case of sample 2, shows the contact width of the wear track between Zr-DLC coatings and SKD11 substrate is a minor wear track coating and no scratches were detected. The wear rate of sample 2 forming similar to glassy carbon, at the level of $4.63 \times 10^{-5} \mathrm{~mm}^{3} / \mathrm{Nm}$, is relatively low comparing to other tests, in which the wear volume with a width of $0.80 \mathrm{~mm}$ is $4.98 \times 10^{-3} \mathrm{~mm}^{3}$ within the $1000 \mathrm{~m}$ sliding distance under a $0.2 \mathrm{~N}$ load. Similarly, in Fig. 4 b, sample 14 displays few slight dimples and long narrow furrows on the worn surface of the coatings. Its wear mechanism is essentially abrasion wear from ploughing and grooving in the worn surface. On the other hand, the level of $6.50 \times 10^{-5} \mathrm{~mm}^{3} / \mathrm{Nm}$ of the wear rate is also low in the sputtering experiments, in which the wear scar volume has a value of $9.16 \times 10^{-3}$ $\mathrm{mm}^{3}$ with the width increasing slightly to the value of $1.30 \mathrm{~mm}$. Fig. $4 \mathrm{c}$ shows the mainly micro-ploughing and brittle fracture scars with a slender area are appeared and the peel-off area of DLC coatings is also produced. As shown in Fig. 4 d, in the higher wear rate coatings, the width of the wear track is very large, the galling and fracture of DLC coatings occurred after $1000 \mathrm{~m}$ sliding and many scratches were induced along the wear direction, in which the wear scar volume is relatively large value of $63.30 \times 10^{-3} \mathrm{~mm}^{3}$ with the width increasing rapidly to the value of $1.85 \mathrm{~mm}$. This is consistent with the result obtained from the SEM images. Clearly, the worn track profile in sample 5 obtained from the present study irregularly fluctuates in the wear track topography while the worn track in sample 2 becomes less undulated to be a comparatively fine texture.

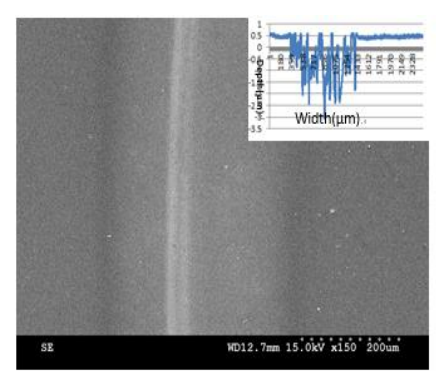

a

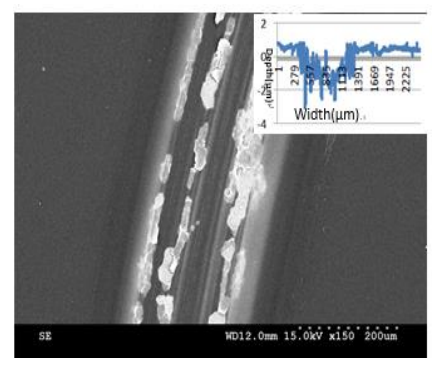

c

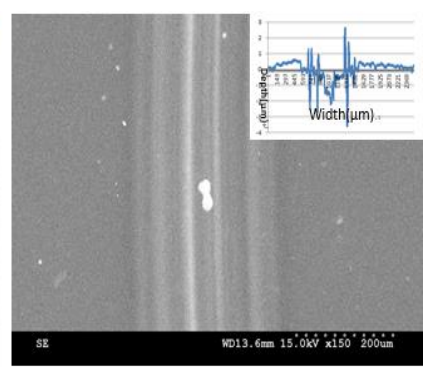

b

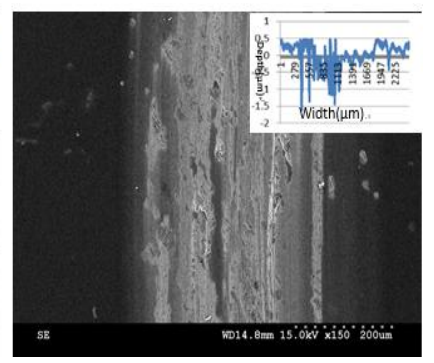

d

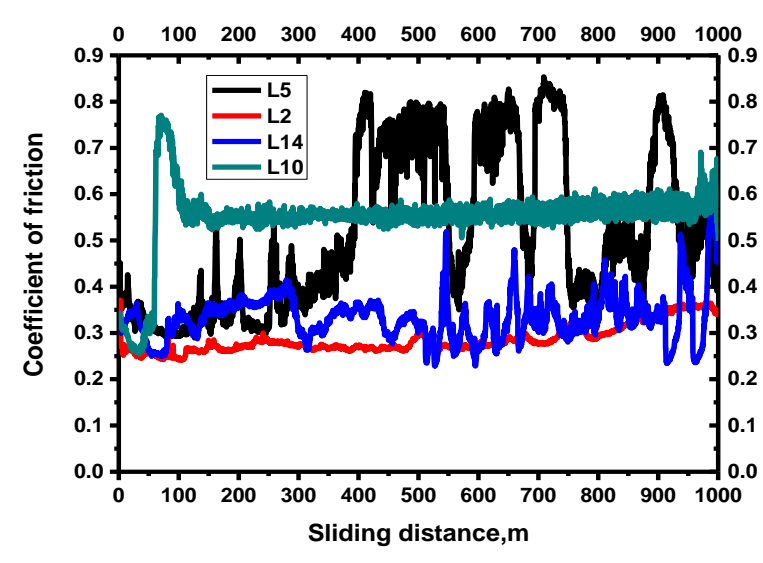

$\mathrm{e}$
Fig. 4. The surface profiles of the wear tracks, the images of the wear track and coefficient of friction for various tests: atrial 2; b-trial $14 ; \mathrm{c}$-trial $10 ; \mathrm{d}$-trial 5 ; e-frictional coefficient curves for $\mathrm{Zr}$-doped DLC coatings in wear tests 
The frictional curve increased from an initially low value to a steady state except sample 5 in all cases. In the case of sample 10 , the COF reduces from 0.77 to 0.56 whereas sample 5 showed a rapid increase slight reduction in increases with the initial to $400 \mathrm{~m}$ from 0.4 to 0.8 , and became instable with drastic fluctuations as sliding distance over sliding $400 \mathrm{~m}$. An increase in the wear rate of the $\mathrm{Zr}$-doped DLC coatings in with a greater COF is clear.

As discussed previously, this can be attributed to the change in lubricant coating from DLC to the $\mathrm{Zr}$-doped DLC lubricant. An increase in the wear rate of the $\mathrm{Zr}$ doped DLC coatings with a greater COF is clear. Overall, the Zr-DLC coatings possessed the higher antiwear properties. This is attributed to the formation of hard $\mathrm{Zr}$ element transfer coating on the worn scar, in which the containing graphite of the Zr-doped DLC coatings in sliding is seen, and the lubricating surface layer is generated. This finding was confirmed by Raman spectroscopy. Therefore, the wear mechanism resulting in lower friction and wear can effectively enhance the antiwear behavior of the Zr-doped DLC coatings.

\subsection{Variable analysis affecting the wear performance}

To determine which variables significantly affect the wear performance of the Zr-doped DLC coatings by magnetron sputtering, ANOVA was used to examine which control variables significantly influenced the quality characteristics of wear rates.

Table 4. Analysis of variance for DLC coatings

\begin{tabular}{|c|c|c|c|c|c|}
\hline Factors & $\begin{array}{c}\text { Sum of } \\
\text { squares }\end{array}$ & $\begin{array}{c}\text { Degrees of } \\
\text { freedom }\end{array}$ & $\begin{array}{c}\text { Mean } \\
\text { square }\end{array}$ & F-value & $\begin{array}{c}\text { Percent } \\
\text { contribution }\end{array}$ \\
\hline A & 10.56 & 2 & 5.28 & 0.31 & 2.45 \\
\hline B & 83.01 & 2 & 41.5 & 2.46 & 19.27 \\
\hline C & 16.49 & 2 & 8.25 & 0.49 & 3.83 \\
\hline D & 48.8 & 2 & 24.4 & 1.45 & 11.33 \\
\hline E & 153.67 & 2 & 76.84 & 4.55 & 35.68 \\
\hline Error & 118.11 & 7 & 16.87 & - & 27.43 \\
\hline Total & 430.65 & 17 & 25.33 & - & 100 \\
\hline
\end{tabular}

Table 4 indicates the ANOVA analysis of the $\mathrm{Zr}$ doped DLC coatings shows the F-distribution for each factor, which allows significant effects to be accepted at $\alpha=0.25$ significance level of each factor on the total variation and shows their degree of influence on the results. The main effects of the factors on the Zr-containing DLC coatings are presented. According to the ANOVA results in Table 4, the most significant three factors are: the frequency (B), stand-off distance (D) and the $\mathrm{C}$ and $\mathrm{Zr}$ target current $(\mathrm{E})$ have maximum effects on the wear rates of the Zr-doped DLC coatings, which together account for about $66.3 \%$ of the total experimental variance. These factors are then further assigned for the modeling of the GA-based ANFIS.

\subsection{GA-based ANFIS analysis}

As aforementioned, the three sputtering deposited factors that have significantly impacts on the tribological properties include pulse frequency (B), sputtering distance (D) and $\mathrm{C} / \mathrm{Zr}$ current (E). Therefore, these deposited variables $\mathrm{B}, \mathrm{D}$ and $\mathrm{E}$ are taken as input features of the ANFIS, and the wear rate is used as the output variable of the ANFIS. Based on the experimental data collected from an orthogonal array design, the quality metamodel of wear rates is built by an ANFIS approach, which was then solved by a GA. To obtain the best predictive performance in the ANFIS model, a GA that has trained the parameters of a Gaussian function for the premise part and a linear equation for the premise part in the ANFIS model can successfully achieve the optimization shown in Fig. 5.

The evolutionary environments of the GA used in this paper are: population size of 200 , crossover rate of 0.9 , mutation rate of 0.1 , and generation number of 200 . Fig. 5 a shows the optimal result of the RMSE for the GAbased ANFIS giving rise to the 200 th generation. Clearly, the proposed GA could find the optimal solution in the ANFIS and the cost function decreased rapidly to the stable state, and resulted in a good prediction with RMSE $=0.00031$. In addition, Figs.5b-5d show the convergent curves of the parameters of a Gaussian function for the three significant variables $(\mathrm{B}, \mathrm{D}, \mathrm{E})$ resulting from the ANOVA table of the Zr-containing DLC coatings in the training processes. It is clear a Gaussian function with parameters $(\alpha, \beta)$ in the premise parts has converged to its stable values after about 200 generations, whereas the convergent values of a linear equation with parameters ( $p$, $\mathrm{q}, \mathrm{r}, \mathrm{t}$ ) in the consequent parts, where the total number of premise and consequent parameters to be found is 126 .

As mentioned above, the optimal parameters of a Gaussian function in the premise part, as well as a linear equation in the consequent part of the GA-based ANFIS for the variables B, D and E can be obtained. On the other hand, the optimal ANFIS design with twenty-seven fuzzy rules can be constructed in the GA train and used to predict the outputs shown in Fig. 1.

\subsection{Predictive analysis using GA-based ANFIS}

To test the predictive ability of the GA-ANFIS, the predicted values were computed as compared with the experimental values of wear rate. The experiments in orthogonal array were divided into two groups for training and testing data of ANFIS. The methodology uses an ANFIS where $70 \%(18 / 23)$ of the available data participates in the learning process with the rest $(5 / 23)$ for testing the predicted values against the observed wear rate. As shown in Fig. 6, the predictions of wear rate with the obtained experimental datum by the three parameters $(\alpha, \beta)$ of a Gaussian function in the optimal GA-based ANFIS model are compared.

Using the GA-based ANFIS approach, in the parameter $(0.3331,0.5880)$ of a Gaussian function, the predicted value of the wear rate obtained in the present study is more accurate due to error function of $9.41 \%$. Overall, the GA-based ANFIS provides a more effective way for searching the optimal ANFIS, because the parameters of a Gaussian function of $(0.3331,0.5880)$, $(0.3331,0.5880)$ and $(0.3331,0.5880)$ could yield the better error functions of $9.41 \%, 9.45 \%$ and $9.58 \%$, respectively. Based on the comparison, a learning ANFIS based on GA that had the best predictive performance was successfully achieved. 


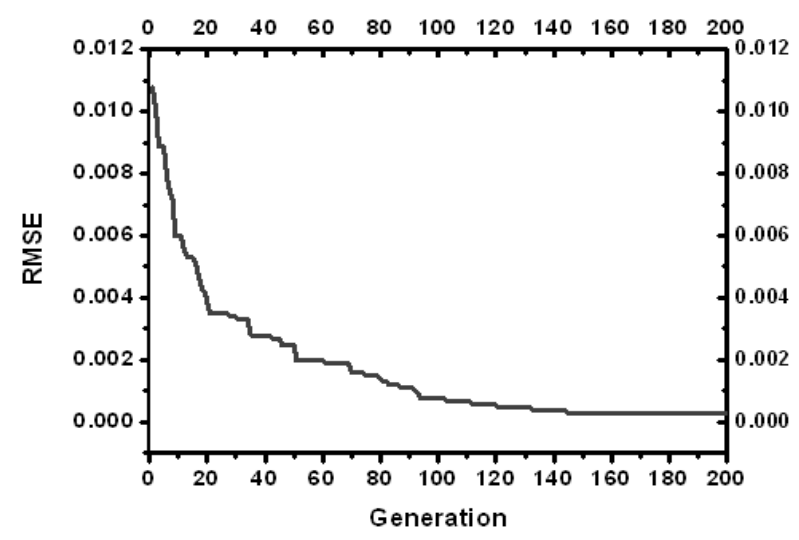

a

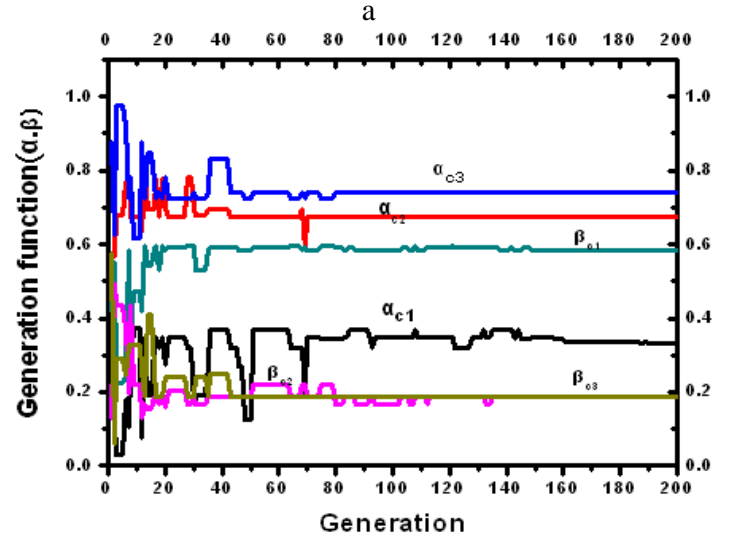

b

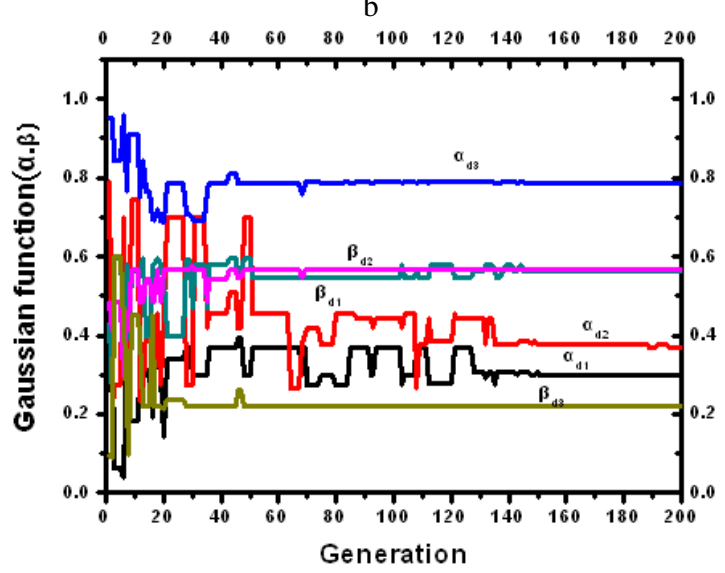

c

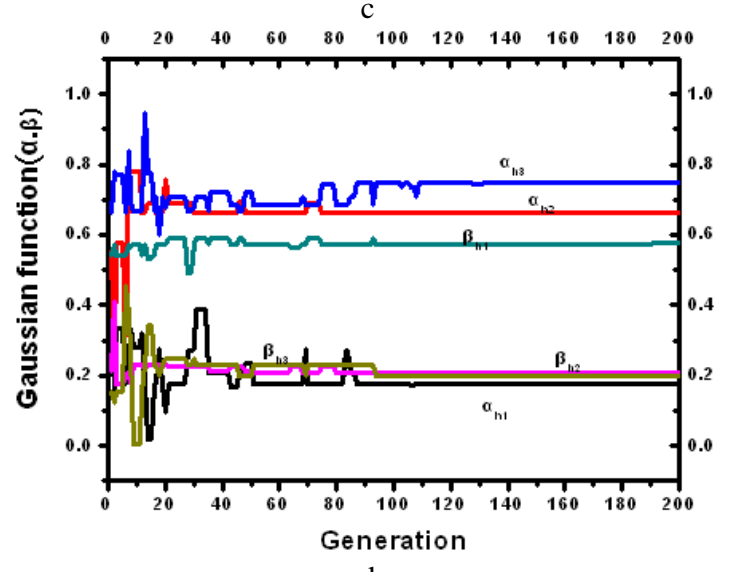

d

Fig. 5. Convergence results of the RMSE curve: a-for the generation; $b$-the optimal premise parameters with a Gaussian function $(\alpha \beta)$ for the input variables; $\mathrm{c}-\mathrm{B}$; $\mathrm{d}-\mathrm{D} ; \mathrm{e}-\mathrm{E}$ by the GA-based ANFIS learning

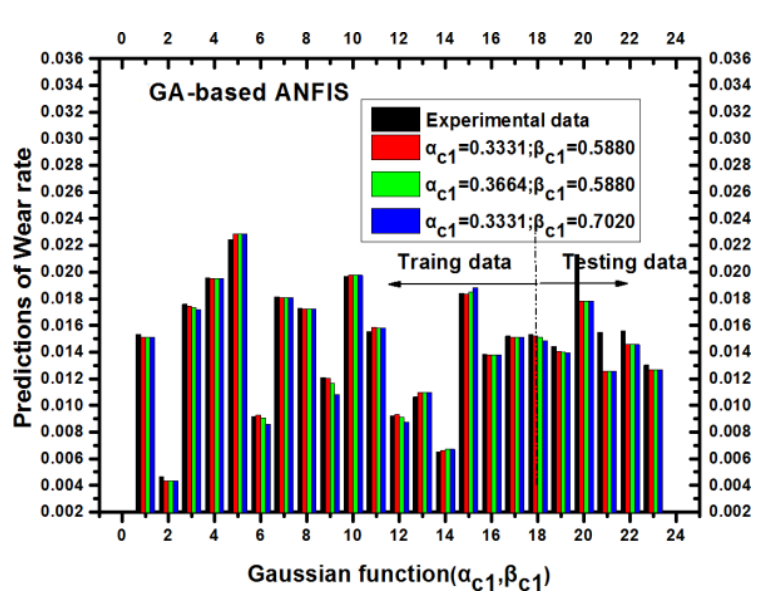

Fig. 6. Modelling comparison predictive ability of ANFIS for the variation effects of the premise parameters with a Gaussian function $(\alpha, \beta)$ for training set of 18 trials and testing set of 5 trials

Importantly, effects of three significant factors including $\mathrm{C} / \mathrm{Zr}$ current, pulse frequency and sputtering distance in ANOVA are considered in turn to predict the relationships between the anti-wear behaviors and variables, and determine the nature. Fig. 7 showed that the predicted patterns of wear rate values for effect of three significant factors including $\mathrm{C} / \mathrm{Zr}$ current, pulse frequency and sputtering distance on the tribological behaviors. A good agreement between the predicted and experimental values was remarked, where the predictors fall into range of average wear rate value with a standard deviation. These results revealed that the GA-based ANFIS model is more closely to the anti-wear behaviors. Clearly, the better predictive ability of the GA-based ANFIS has been successfully achieved. In addition, Fig. 7 a depicts the influence of $\mathrm{C} / \mathrm{Zr}$ current on anti-wear behaviors. Wear rate values are found to decrease with the increase of $\mathrm{C} / \mathrm{Zr}$ current ranged from 2.3/0.3(A) to 2.3/1.1(A), especially existing the lowest wear rate at 2.3/0.7(A). This decrease can be attributed to the half estimated value of $\mathrm{sp}^{3} / \mathrm{sp}^{2}$ ratio that efficiently improve lubrication at the interface in wear contacts, which is consistent with the literature [10], which the $\mathrm{C} / \mathrm{Zr}$ current is found to be more sensitive to wear rate and exhibited extremely decrease at high levels. This finding was confirmed by Raman spectroscopy. As shown in the pulse frequency effect from Fig. $7 \mathrm{~b}$, it is clear the pulse frequency has an inversely proportional relationship with the wear rate. Wear rate values decrease with the increase of the pulse frequency, where the increase in the pulse frequency is not favorable to the anti-wear behaviors. This finding is in good agreement with that found shown in literature [24]. These arguments suggested the decrease of carbon contents and the increase of $\mathrm{Zr}$ elements in the coatings. As a result of Zr-DLC coatings, the coatings hardened, which decreased the wear. Fig. $7 \mathrm{c}$ showed the influence of sputtering distance on adhesive force. At a longer sputtering distance, this phenomenon caused a reduction of deposited rate in the Zr-DLC coatings, thus the adhesive strength of coatings is reduced and resulted in the highest wear volume, where the increase in the sputtering distance relatively decreases the anti-wear behaviors. As seen in the above figures, it was 
experimentally confirmed that GA-ANFIS predictions agree with the experimental results.

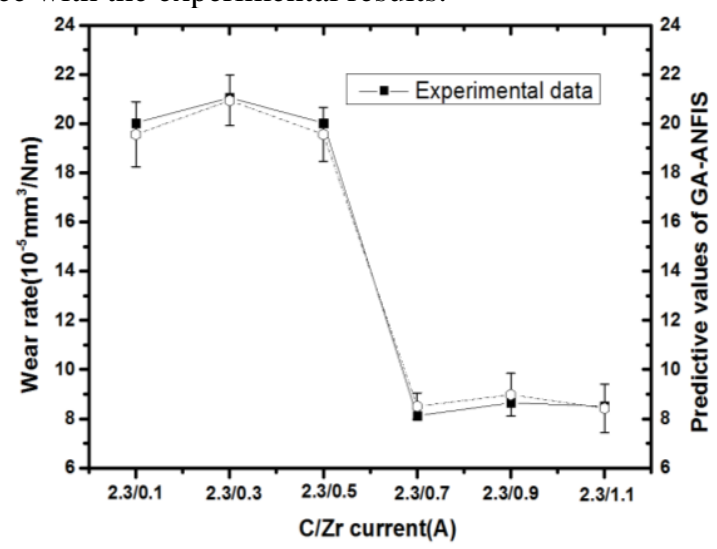

a

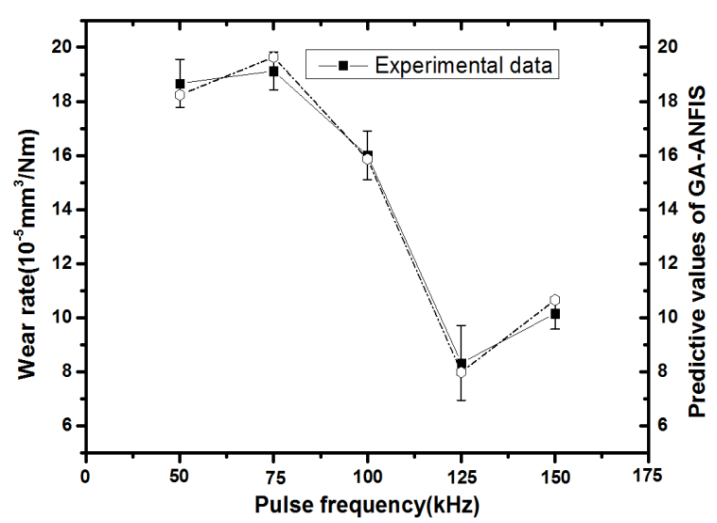

b

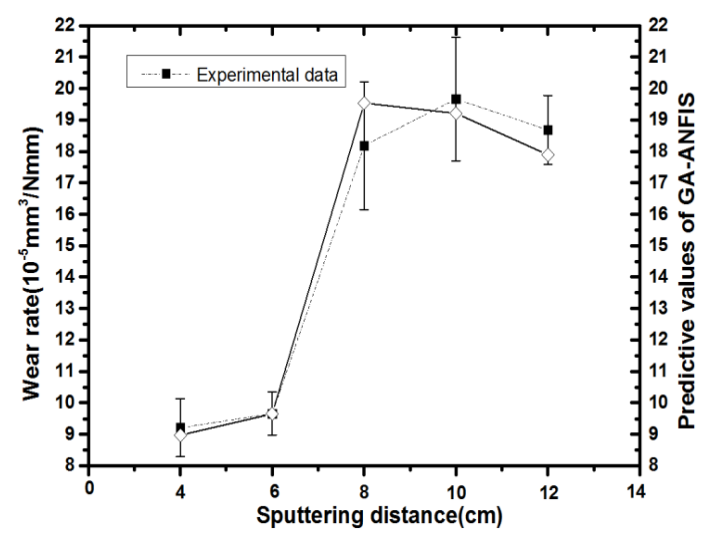

c

Fig. 7. The predicted patterns of wear rate values for three significant factors including: $\mathrm{a}-\mathrm{C} / \mathrm{Zr}$ current; $\mathrm{b}-$ pulse frequency; $\mathrm{c}$-sputtering distance on the tribological behavior

\section{CONCLUDING REMARKS}

The functional graded $\mathrm{Zr}$-DLC coatings were synthesized by magnetron sputtering. Microstructural evolution and tribological behaviors of the Zr-DLC coatings were studied. In addition, the GA-ANFIS approach has been proved to be more accurate for forecasting the tribological properties of the $\mathrm{Zr}$-DLC coatings. Based on the experimental results, the following conclusions are drawn:
1. In this work, a well-adhered Zr-DLC coatings based on two interlayers as $\mathrm{ZrZZrC}$ elements has been successfully fabricated on the SKD11 by sputtering depositions. The Zr-DLC coatings gain dense structures with uniformly distributed nanoparticle phases. Raman analyses revealed that the Zr-DLC coatings at lower ID/IG ratio possess higher microhardness, better scratch strength and better wear resistance. In addition, the tribological behavior of the Zr-DLC coatings coated SKD11 provides a favorable wear resistance over that of SKD11substrate.

2. In ANOVA, the important factors are identified. The $\mathrm{C}$ and $\mathrm{Zr}$ target current, sputtering distance and pulse frequency accounting for nearly $66.30 \%$ of the experimental variation are significantly affected for the tribological behaviors of the Zr-DLC coatings. The worn surface with a glassy carbon phase seems to appear at lower ID/IG ratio in the Zr-DLC coatings, where the Zr-DLC coatings with slight worn scar textures are clearly visible in the worn track studied. Furthermore, the SEM micrographs of worn surface of DLC coatings are examined in the EDS spectrum. No significant difference between zirconium elements of the DLC coatings is found.

3. In this study, the use of GA-ANFIS can gain the suitable membership functions and find the optimal parameters in the ANFIS model, yielding the effectiveness of predicting the tribological properties of the Zr-DLC coatings. In addition, the values predicted by the GA-ANFIS best fit the data, where error function of the predicted value of the wear rate obtained in the present study is $9.41 \%$. Clearly, the GA-ANFIS provides a good prediction within the experimental domains.

\section{Acknowledgement}

This work was financially supported by the Ministry of Science and Technology (grants MOST 108-2218-E-992304, MOST 108-2221-E-037-007) and the "Intelligent Manufacturing Research Center" (iMRC) from the Featured Areas Research Center Program within the framework of the Higher Education Sprout Project by the Ministry of Education (MOE).

\section{REFERENCES}

1. Gulbiński, W., Mathur, S., Shen, H., Suszko, T., Gilewicz, A., Warcholiński, B. Evaluation of Phase, Composition, Microstructure and Properties in TiC/a-C:H Thin Films Deposited by Magnetron Sputtering Applied Surface Science 239 2005: pp. 302-310. https://doi.org/10.1016/j.apsusc.2004.05.278

2. Sun, C.C., Lee, S.C., Dai, S.B., Fu, Y.S., Wang, Y.C., Lee, Y.H. Surface Free Energy of CrNx Films Deposited Using Closed Field Unbalanced Magnetron Sputtering Applied Surface Science 252 2006: pp. 8295-8300. https://doi.org/10.1016/j.apsusc.2005.10.055

3. Sunil, K.P., Jiang, J., Meletis, EI. Effects of N-Doping on the Microstructure, Mechanical and Tribological Behavior of Cr-DLC Films Surface \& Coatings Technology 201 2007: pp. 7917-7923. https://doi.org/10.1016/j.surfcoat.2007.03.036 
4. Inkin, V.N., Kirpilenko, G.G., Dementjev, A.A., Maslakov, K.I. A Superhard Diamond-Like Carbon Film Diamond and Related Materials 9 2000: pp. 715-721. https://doi.org/10.1016/S0925-9635(99)00344-1

5. Chang, Y.Y., Wang, D.Y., Chang, C.H., Wu, W.T. Tribological Analysis of Nano-Composite Diamond-Like Carbon Films Deposited by Unbalanced Magnetron Sputtering Surface and Coatings Technology 184 2004: pp. 349-355. https://doi.org/10.1016/j.surfcoat.2003.11.015

6. Polychronopoulou, K., ebholz, C.,

Baker, MA., Theodorou, L., Demas, N.G. Hinder, S.J. Polycarpou, A.A., $\quad$ Doumanidis, C.C., $\quad$ Böbel, K. Nanostructure, Mechanical and Tribological Properties of Reactive Magnetron Sputtered TiCx Coatings Diamond \& Related Materials $17 \quad$ 2008: pp. 2054-2061. https://doi.org/10.1016/j.diamond.2008.07.007

7. Kao, W.H. The Tribological Properties of $\mathrm{Zr}-\mathrm{C}: \mathrm{H}$ Coatings Deposited on AISI M2 Substrate Wear 264 2008: pp. $368-373$ https://doi.org/10.1016/j.wear.2007.01.117.

8. Sheeja, D., Tay, B.K., Krishnan, S.M., Nung, L.N. Tribological Characterization of Diamond-Like Carbon (DLC) Coatings Sliding against DLC Coatings Diamond and Related Materials 12 2003: pp. 1389-1395. https://doi.org/10.1016/S0925-9635(03)00165-1

9. Elman, B.S., Dresselhaus, M.S., Dresselhaus, G., Maby, E.W., Mazurek, H. Raman Scattering from IonImplanted Graphite Physical Review B 24 1981: pp. $1027-1034$. https://doi.org/10.1103/PhysRevB.24.1027

10. Paik, N.W. Raman and XPS Studies of DLC Films Prepared by a Magnetron Sputter-type Negative Ion Source Surface \& Coatings Technology 200 2005: pp. 2170-2174. https://doi.org/10.1016/j.surfcoat.2004.08.073

11. Kao, W.H., Su, Y.L., Yao, S.H. Tribology Property and Drilling Application of Ti-C:H- and Cr-C:H Coatings on High-Speed Substrates Vacuum 80 2006: pp. $604-614$. https://doi.org/10.1016/j.vacuum.2005.10.005

12. Lin, C.T., Lee, C.S. Neural Fuzzy System: A Neural-Fuzzy Synergism to Intelligent Systems Prentice Hall Simon \& Schuster 1996: pp. 205-262.

13. Pander, A., Hatta, A., Furuta, H. Optimization of Catalyst Formation Conditions for Synthesis of Carbon Nanotubes Using Taguchi Method Applied Surface Science 371 2016: pp. $425-435$. https://doi.org/10.1016/j.apsusc.2016.02.216

14. Jean, M.D., Lin, B.T., Chou, J.H. Design of a Fuzzy Logic Approach Based on Genetic Algorithms for Robust PlasmaSprayed Zirconia Depositions Acta Materialia 55 2007: pp. 1985-1997. https://doi.org/10.1016/j.actamat.2006.11.011

15. Nemnes, G.A., Iftimie, S., Palici, A., Nicolaev, A., Mitran, T.L., Radu, A., Antohe, S. Optimization of the Structural Configuration of ICBA/P3HT Photovoltaic Cells Applied Surface Science 290 2017: pp. 264-268. https://doi.org/10.1016/j.apsusc.2017.05.002

16. Gen, M., Cheng, R. Genetic Algorithms and Engineering Design. John Wiley and Sons, 1997: pp. 25-42.

17. Goldberg, D.E. Genetic Algorithms in Search, Optimization and Machine Learning. Addison-Wesley, 1989: pp. 68-96.
18. Tsai, J.T., Liu, T.K., Chou, J.H., Wu, Y.J. Hybrid Taguchi-Genetic Algorithms for Global Numerical Optimization IEEE Transactions on Evolutionary Computation 8 2004: pp. 365-377. https://doi.org/10.1109/tevc.2004.826895

19. Tsai, J.T., Chou, J.H., Liu, T.K. Tuning the Structure and Parameters of a Neural Network by Using Hybrid TaguchiGenetic Algorithm IEEE Transactions. on Neural Networks 17 2006: pp. 69-80. https://doi.org/10.1109/TNN.2005.860885

20. Jean, M.D., Chien, T.H., Chang, H., Fang, J. Analysis and Simulation for Properties and Performance of CarbonNitrogen-Ceramic Multilayer Coatings Journal of Computational and Theoretical Nanoscience 7 (8) 2010: pp. $1447-1456$. https://doi.org/10.1166/jctn.2010.1502

21. Arslan, A., Masjuki, H.H., Varman, M., Kalam, M.A., Quazi, M.M., $\quad$ Al Mahmud, K.A.H., $\quad$ Gulzar, M., Habibullah, M. Effects of Texture Diameter and Depth on the Tribological Performance of DLC Coating under Lubricated Sliding Condition Applied Surface Science 356 2015: pp. $1135-1149$.

https://doi.org/10.1016/j.apsusc. 2015.08.194

22. Vitu, T., Escudeiro, A., Polcar, T., Cavaleiro, A. Sliding Properties of Zr-DLC Coatings: The Effect of Tribolayer Formation Surface \& Coatings Technology 258 2014: pp. 734-745. https://doi.org/10.1016/j.surfcoat.2014.08.003

23. MSc, H.B., Amani, A. Cytotoxicity of Chitosan/Streptokinase Nanoparticles as a Function of Size: An Artificial Neural Networks Study Nanomedicine: Nanotechnology, Biology, and Medicine 12 2016: pp. $171-180$. https://doi.org/10.1016/j.nano.2015.09.002

24. Chen, Y., Wu, J.M., Nie, X.Y., Yu, S.F. Study on Failure Mechanisms of DLC Coated Ti6Al4V and $\mathrm{CoCr}$ under Cyclic High Combined Contact Stress Journal of Alloys and Compounds 688 2016: pp.964-973. https://doi.org/10.1016/j.jallcom.2016.07.254

25. Staia, M.H., Puchi Cabrera, E.S., Iost, A., Zairi, A., Belayer, S., Van Gorp, A. Tribological Response of AA 2024-T3 Aluminium Alloy Coated with a DLC Duplex Coating Tribology International 85 2015: pp. $74-87$. https://doi.org/10.1016/j.triboint.2014.12.007

26. Solis, J., Zhao, H., Wang, C., Verduzco, J.A., Bueno, A.S., Neville, A. Tribological Performance of an H-DLC Coating Prepared by PECVD Applied Surface Science 383 2016: pp. $222-232$. https://doi.org/10.1016/j.apsusc.2016.04.184

27. Li, A.J., Li, H.J., Li, K.Z, Gu, Z.B. Applications of Neural Networks and Genetic Algorithms to CVI Processes in Carbon/Carbon Composites Acta Materialia 52 (2) 2004: pp. 299-305. https://doi.org/10.1016/j.actamat.2003.09.020

28. Xu, W., Rivera-Dıáz-del-Castillob, P.E.J., Wang, W., Yang, K., $\quad$ Bliznuk, V., $\quad$ Kestens, V.L.A.I., Van der Zwaag, S. Genetic Design and Characterization of Novel Ultra-High-Strength Stainless Steels Strengthened by Ni3Ti Intermetallic Nanoprecipitates Acta Materialia 58 2010: pp. $3582-3593$. https://doi.org/10.1016/j.actamat.2010.02.028

29. Huang, H., Sherif, M.Y., Rivera-Dǐaz-del-Castillo, P.E.J. Combinatorial Optimization of Carbide-Free Bainitic 
Nanostructures Acta Materialia 61

2013: pp. $1639-1647$.

https://doi.org/10.1016/j.actamat.2012.11.040

30. Zhu, Q

Abbod, M.F.,

Talamantes-Silva, J., Sellars, C.M., Linkens, D.A., Beynon, J.H. Hybrid Modelling of Aluminium-Magnesium Alloys during Thermomechanical Processing in Terms of Physically-Based, Neuro-Fuzzy and Finite Element Models Acta Materialia 51 (17) 2003: pp. 5051-5062. https://doi.org/10.1016/s1359-6454(03)00353

31. Guessasma, S., Bassir, D. Optimization of the Mechanical Properties of Virtual Porous Solids Using a Hybrid
Approach Acta Materialia 58 (2)

2010: pp. 716-725.

https://doi.org/10.1016/j.actamat.2009.09.051

32. Lemoine, $\mathbf{P}$.,

Quinn, J.P.,

Maguire, P.D.

McLaughlin, J.A.D. Measuring the Thickness of Ultra-Thin

Diamond-Like Carbon Films Carbon 44

2006: pp. $2617-2624$.

https://doi.org/10.1016/j.carbon.2006.04.029

33. Womack, G., Kaminski, P.M., Walls, J.M. Optical Optimization of High Resistance Transparent Layers in Thin Film Cadmium Telluride Solar Cells Vacuum 139 2017: pp. $196-201$

https://doi.org/10.1016/j.vacuum.2017.02.018 